\title{
INOVASI PENGEMBANGAN POTENSI WANADESA SEBAGAI UPAYA PENGELOLAAN LINGKUNGAN DI KABUPATEN BANTUL DAERAH ISTIMEWA YOGYAKARTA
}

\author{
Dwi Herniti ${ }^{1}$, Endro Waluyo ${ }^{2}$, Gerson Wisang ${ }^{3}$ \\ ${ }^{1}$ Dosen Teknik Pertambangan, Institut Teknologi Yogyakarta \\ dwi.herniti@gmail.com \\ ${ }^{2}$ Badan Lingkungan Hidup DIY \\ ${ }^{3}$ Konsultan Trisakti Pilar Persada
}

\begin{abstract}
ABSTRAK
Saat ini permasalahan lingkungan semakin kompleks akibat semakin meningkatnya berbagai tuntutan kehidupan sosial ekonomi masyarakat baik skala lokal, nasional, atau global, Salah satunya terkait dengan terjadinya perubahan iklim (climate change) yang menyebabkan banjir, kekeringan, pencemaran udara dan air serta bencana lainnya. Wanadesa adalah suatu kegiatan pendayagunan lahan desa dengan menambah atau meningkatkan jumlah tanaman (vegetasi) yang bertujuan meningkatkan ruang bebas guna mendukung upaya konservasi lingkungan.

Pengembangan pengelolaan wanadesa di Kabupaten Bantul dilakukan dengan beberapa upaya meliputi penyiapan kelompok lembaga pengelola melalui penyuluhan dan penyusunan perangkat aturan/kesepakatan internal kelompok pengelola wanadesa, penataan areal tanaman di lahan wanadesa, pembuatan sarana prasarana pendukung, penanaman serta pemeliharaan tanaman. Jenis tanaman yang ditanam pada lahan wanadesa meliputi tanaman ekonomi dan tanaman perindang, sehingga selain sebagai upaya peningkatan pengelolaan lingkungan juga dapat meningkatkan ekonomi daerah dari hasil lahan wanadesa.
\end{abstract}

Kata Kunci : Inovasi, Wanadesa, Pengelolaan Lingkungan

\section{(POTENTIAL DEVELOPMENT INNOVATION OF VILLAGE OWNED FOREST AS ENVIRONMENTAL MANAGEMENT EFFORTS IN BANTUL REGENCY, SPECIAL REGION OF YOGYAKARTA)}

\begin{abstract}
Increasingly complex environmental problems are accompanied by the increasing demands of the community's socio-economic life both locally, nationally and even globally. One of them is related to climate change that causes floods, droughts, air and water pollution and other disasters. The village is an activity of empowering village land by increasing or increasing the number of plants (vegetation) which aims to increase free space to support environmental
\end{abstract}


conservation efforts. The development of rural water management in Bantul Regency is carried out with several efforts including the preparation of management agency groups through counseling and preparation of internal rules / agreement groups for village management groups, structuring of plant areas on the village owned forest land, making supporting infrastructure, planting and maintaining plants. The types of crops planted on the village owned forest land include economic crops and shade crops, so that in addition to efforts to improve environmental management can also improve the regional economy of the agricultural land

Keywords:innovation, village owned forest, environmental management

\section{PENDAHULUAN}

\section{LATAR BELAKANG}

Kerangka keistimewaan DIY dengan makna Hamemayu Hayuning Bawono adalah mengandung makna menjaga Bawana atau dunia ini tetap Hayu yang bermakna indah dan Rahayu yang bermakna lestari. Konsep ini mengandung makna sebagai kewajiban melindungi, memelihara, serta membina keselamatan dunia dan lebih mengedepankan kepentingan masyarakat daripada kepentingan pribadi maupun kelompok. Makna kekinian dari Hamemayu Hayuning Bawono adalah paradigma pembangunan berkelanjutan yang berorientasi pada kepentingan masyarakat tanpa mengorbankan kepentingan generasi di masa depan. Agar pembangunan dapat berkelanjutan tidak cukup hanya memperhatikan faktor lingkungan hidup saja tetapi harus dilandasi dengan etika dan memperhatikan pilar ekonomi dan sosial budaya.

Usaha meningkatkan kualitas lingkungan dalam kerangka keistimewaan perlu sinergi dengan budaya dan adat istiadat Daerah
Istimewa Yogyakarta. Salah satunya adalah usaha meningkatkan kondisi kualitas udara melalui pengembangan kegiatan inisiasi Wanadesa. Wanadesa adalah suatu kegiatan pendayagunaan lahan desa dengan menambah atau meningkatkan jumlah tanaman (vegetasi) yang bertujuan meningkatkan ruang bebas guna mendukung upaya konservasi lingkungan (Waluyo,2014). Berbagai tantangan yang dihadapi wilayah perdesaan di negara berkembang saat ini antara lain adalah mewujudkan ketahanan pangan, mitigasi dan adaptasi terhadap perubahan iklim, melindungi keanekaragaman hayati sementara pada saat yang sama juga meningkatkan pertumbuhan ekonomi, melindungì orang-orang dari bencana alam, mencegah, dan menyelesaikan konflik lahan serta pembangunan lingkungan (Sitorus, 2016).

Kegiatan tersebut selain sebagai usaha meningkatkan kualitas lingkungan (konservasi lingkungan) juga dimaksudkan untuk meningkatkan kelestarian tanaman langka sebagai wujud pengembangan taman keanekaragaman hayati dan 
ekosistem flora (tanaman langka).

Disamping itu juga untuk mendukung peningkatan cadangan air tanah permukaan. Kegiatan tersebut juga menginisiasi upaya mendukung pengembangan tata ruang di Daerah Istimewa Yogyakarta khususnya Ruang Terbuka Hijau.

Kegiatan wanadesa dilakukan secara berkelanjutan guna terpenuhinya target tutupan vegetasi melalui pola kerja sama dengan pemerintah desa untuk melakukan konservasi terhadap sebagaian lahan yang dikuasai. Model pola kerjasama dengan pemerintah desa dengan Pemerintah DIY yang terwadahi dalam program Wanadesa diharapkan sebagai salah satu strategi dalam upaya konservasi lingkungan.

\section{PERMASALAHAN}

Permasalahan lingkungan yang semakin kompleks diiringi dengan semakin meningkatnya berbagai tuntutan kehidupan sosial ekonomi masyarakat baik skala lokal, nasional, bahkan global, Salah satunya terkait dengan terjadinya perubahan iklim (climate change) yang menyebabkan banjir, kekeringan, pencemaran udara dan air serta bencana lainnya.

Saat ini tutupan vegetasi di DIY baru mencapai $23,67 \%$, jadi kegiatan Wanadesa merupakan salah satu upaya untuk mencapai target kekurangan tutupan vegetasi tersebut.

\section{TUJUAN}

1. Membuat rencana-rencana kegiatan yang mendukung upaya pengelolaan Wanadesa sebagai bagian konservasi lingkungan;

2. Mensinergiskan pengelolaan Wanadesa dengan kegiatankegiatan pendukung;

3. Merumuskan serta mengarahkan rencana teknis dan pembuatan peta tata lingkungan di kawasan Wanadesa;

4. Memberikan arahan sistem pengelolaan Wanadesa di 3 lokasi di Kabupaten Bantul

\section{TINJAUAN PUSTAKA}

Wanadesa adalah suatu kegiatan pendayagunan lahan desa dengan menambah atau meningkatkan jumlah tanaman (vegetasi) yang bertujuan meningkatkan ruang bebas guna mendukung upaya konservasi lingkungan. Kegiatan Wanadesa yang diarahkan pada upaya membangun sinergi antara pemerintah dan masyarakat desa, dalam mewujudkan upaya konservasi lingkungan melalui pemberdayaan masyarakat, penguatan kelembagaan dan pengembangan potensi desa di kawasan Wanadesa.

Lahan Wanadesa terdiri dari tanah kas desa, Sultan Ground dan Pakualam Ground. Ketiga jenis kepemilikan lahan tersebut dikuasai oleh pemerintah desa. Tanah yang 
dipakai untuk program tersebut adalah tanah yang paling tidak produktif di desa itu.

Tanaman yang boleh ditanam adalah tanaman yang menghasilkan getah, buah dan daun. Selain itu tanaman yang tidak tebang habis dan tanaman konservasi. Tanaman yang sudah diserahkan untuk program wanadesa tidak boleh ada alih hak dan alih fungsi.

Program wanadesa

merupakan amanat dari Peraturan

Menteri Lingkungan Hidup No.1

Tahun 2012 tentang Menuju

Indonesia Hijau sebagai tindak lanjut dari perintah Undang-undang Nomor: 41 Tahun 1999 tentang Kehutanan bahwa setiap Daerah Aliran Sungai (DAS) harus menyisakan $30 \%$ sebagai daerah yang terkonservasi.

Secara umum ciri-ciri Bibit tanaman pada lahan Wanadesa adalah berkualitas dan layak tanam yaitu tanaman yang memiliki kualitas yang unggul tentunya juga berasal dari bibit yang unggul. Pemilihan bibit sebagai cikal bakal tanaman sangat berperan penting dalam menciptakan sebuah tanaman yang memiliki kualitas unggul. Setiap jenis tanaman memiliki ciriciri dan model bibit yang berbedabeda. Sebuah bibit bisa dikatakan berkualitas apabila memiliki beberapa ciri umum diantaranya adalah:

1. Pertumbuhan Bibit Seragam
Bibit dikatakan memiliki kualitas yang unggul apabila saat ditanam secara serempak, juga akan tumbuh secara serempak. Tak ada bibit yang sebagian tumbuh dengan sangat baik dan sebagian lainnya lagi mati. Jika memang ada bibit semacam itu berarti bibit tersebut tidak bisa dikatakan sebagai bibit yang berkualitas.

2. Tahan Saat Dipindah

Bibit berkualitas unggul memiliki ciri-ciri apabila saat dipindah dari tempat satu ke tempat lain tidak mati. Biasanya beberapa jenis bibit tanaman harus disiangi terlebih dahulu sebelum ditanam agar bisa tumbuh dengan baik. Nah, jika bibit tanaman mudah mati dan tidak bisa tumbuh dengan baik saat dipindah dari tempat penyiangan ke dalam lahan tanam, berarti bibit tersebut kurang memiliki kualitas yang unggul.

3. Tumbuh Lebih Cepat

Selain itu, bibit yang memiliki kualitas unggul dapat tumbuh dengan cepat saat ditanam. Namun dengan catatan seperti yang telah disebutkan tadi, bahwa tumbuhnya juga harus seragam atau serempak. Jadi kesimpulannya, bibit yang berkualitas unggul tumbuhnya lebih cepat dan serempak.

4. Memiliki Akar Yang Banyak

Bibit yang berkualitas juga memiliki ciri-ciri memiliki akar yang banyak. Misal bibit padi 
yang memiliki akar serabut subur akan lebih cepat hidup dan tumbuh besar dibanding dengan yang akarnya sedikit, karena akar sendiri merupakan jalan masuk makanan untuk tumbuhan.

5. Kokoh dan Menghijau

Bibit tanaman yang berkualitas juga memiliki ciri-ciri fisik yang kokoh dan berwarna kehijauan alias tidak layu. Bibit seperti itu dapat tumbuh dengan cepat saat ditanam.

6. Tahan Terhadap Hama

Ciri-ciri bibit yang memiliki kualitas unggul adalah tahan terhadap berbagai macam serangan hama saat sudah ditanam. Bibit yang seperti ini dikatakan unggul karena bisa menghemat biaya perawatan karena tidak perlu lagi perlakukan khusus untuk menekan serangan hama pada tumbuhan. Selain itu bibit yang tahan hama akan mampu memberikan hasil panen yang baik.

7. Tahan Terhadap Perubahan Iklim Salah satu ciri dari bibit tanaman yang memiliki kualitas unggul adalah yang tahan terhadap berbagai perubahan iklim saat sudah ditanam. Bibit yang tahan iklim akan membuat tanaman tidak mudah mati saat sudah ditanam dalam menghadapi perubahan iklim, misal dari penghujan ke kemarau, atau sebaiknya

8. Produktivitas Tinggi
Hal terpenting yang dapat menandai bahwa bibit dikatakan unggul apabila hasil produk yang dihasilkan oleh bibit itu tinggi, baik dari segi kualitas maupun kuantitas. Biasa nilai ekonomis yang ditawarkan oleh bibit dengan tingkat produktivitas tinggi juga cukup mahal.

Kemudian Spesifikasi Bibit Tanaman berdasarkan jenis tanaman buah, tanaman perkebunan dan tanaman kayu antara lain :

a. Tanaman Pokok Buah

1) Jenis/varietas unggul (cepat berbuah, produksi tinggi, rasa enak)

2) Jenis bibit hasil okulasi/ sambungan dari jenis pohon buah terpilih.

3) Ketinggian bibit berukuran 100-120 Cm diukur dari permukaan tanah dalam polybag.

4) Bibit tanaman berada didalam polybag.

5) Bibit dalam kondisi sehat.

6) Posisi batang kokoh dan tegak tumbuh ke atas secara proporsional.

7) Ada sertifikasi kualitas bibit dari lembaga formal yang berwewenang

b. Tanaman Perkebunan

1) Jenis/varietas unggul (cepat pertumbuhan, produksi tinggi, kualitas kayu baik), yang dicirikan dengan adanya label sertifikasi dari lembaga yang berwenang. 
2) Jenis bibit dari jenis pohon perkebunan terpilih.

3) Ketinggian bibit $100 \mathrm{~cm}$ dari permukaan tanah dalam polybag

4) Tanaman bibit dalam polybag

5) Bibit dalam kondisi sehat.

6) Posisi batang kokoh dan tegak tumbuh ke atas secara proporsional.

7) Ada sertifikasi kualitas bibit dari lembaga formal yang berwewenang.

c. Tanaman Kayu

1) Jenis/ varietas unggul (cepat pertumbuhan, produksi tinggi, kualitas kayu baik), ditandai dengan adanya label/ sertifikasi dari lembaga yang berwenang, misalnya BPTH (Balai Perbenihan Tanaman Hutan), jika merupakan tanaman hutan.

2) Jenis bibit dari jenis pohon kayu terpilih.

3) Ketinggian bibit $80 \mathrm{Cm}$ dari permukaan tanah dalam polybag

4) Tanaman bibit dalam polybag

5) Bibit dalam kondisi sehat.

6) Posisi batang kokoh dan tegak tumbuh ke atas secara proporsional.

\section{DATA}

\section{a. Data Primer}

Data primer dalam penelitian ini adalah sebagai berikut :

1. Luas Lahan Wanadesa

2. Vegetasi atau pekerjaan penanaman sebelumnya
3. Tingkat hidup dari tanaman yang sudah ditanam

4. Tanaman lokal atau tanaman langka yang sudah ada

5. Peran serta masyarakat dalam kegiatan Wanadesa

\section{b. Data Sekunder}

Data sekunder dalam penelitian ini adalah sebagai berikut :

1. Peta administrasi Kabupaten Bantul

2. Peta lokasi Wanadesa

3. Data jenis tanaman dan jumlah bibit yang sudah ditanam

4. Data kinerja lembaga pengelola Wanadesa

5. Daftar harga bibit tanaman dan bahan pendukung dalam penanaman.

\section{Metode Pengumpulan Data}

Penelitian ini terdapat dua objek pengambilan data. Objek pertama mengenai lokasi Wanadesa menggunakan GPS. Koordinat lokasi Wanadesa ditandai dengan GPS. Koordinat yang telah diperoleh dengan GPS kemudian dimasukkan dalam software ArcGIS untuk diolah lebih lanjut menjadi peta lokasi dan peta kondisi lahan Wanadesa eksisting. Objek pengambilan data yang kedua adalah kondisi biofisik lokasi Wanadesa. Pengambilan data biofisik berupa data jenis dan kerapatan vegetasi yang diperoleh dari interpretasi visual citra satelit dan pengamatan lapangan. Tujuan pengambilan data biofisik tersebut 
bertujuan untuk mengetahui jenis tanaman eksisting pada lahan Wanadesa dan kondisinya jika dibandingkan dengan data sekunder berupa data jumlah dan jenis bibit yang ditanam.

\section{Analisis Data}

Tahapan dalam pengolahan data meliputi;

1. Kajian inisiasi Wanadesa, tahap ini melakukan kajian potensi lahan yang dikuasai oleh pemerintah desa guna menentukan kriteria desain atas rancangan Wanadesa.

2. Merancang desain Wanadesa serta lokasi yang sudah ditetapkan untuk dibangun/ dikembangkan sebagai Wanadesa, maka harus dirancang baik rancangan teknis pola tanam maupun rancangan teknis pendukung atas pengelolaannya.

\section{HASIL DAN PEMBAHASAN}

Berdasarkan hasil observasi lapangan maka kondisi lahan Wanadesa di kabupaten Bantul adalah sebagai berikut

Tabel 1. Luas Lahan Wanadesa Kab. Bantul

\begin{tabular}{|c|l|c|c|c|}
\hline \multirow{2}{*}{ No } & \multicolumn{1}{|c|}{ Desa } & \multicolumn{3}{|c|}{ Luasan Lahan (Ha) } \\
\cline { 3 - 5 } & $\begin{array}{c}\text { Efektif } \\
\text { Penanaman } \\
\text { (Lahan } \\
\text { Kosong) }\end{array}$ & $\begin{array}{c}\text { Kurang } \\
\text { Efektif } \\
\text { Penanaman } \\
\text { (Terdapat } \\
\text { Vegetasi) }\end{array}$ & Total \\
\hline 1 & Tamanan & 0.74 & 0.18 & 0.92 \\
\hline 2 & Singosaren & 1.29 & 0.35 & 1.64 \\
\hline 3 & Wirokerten (3 Lokasi) & \multicolumn{3}{l}{} \\
\hline & Wirokerten I & 0.58 & 0.12 & 0.7 \\
\hline & Wirokerten Ii & 1.11 & 0.04 & 1.15 \\
\hline & Wirokerten Iii & 0.53 & 0.05 & 0.58 \\
\hline Jumlah Lahan & 2.22 & 0.21 & 6.89 \\
\hline
\end{tabular}

Sumber : Data Survei, 2017
Lokasi yang paling luas berada di Desa Wirokerten Kecamatan Banguntapan dengan luas 2,43 Ha, dengan efektifitas paling besar yaitu 2,22 Ha, sedangkan perencanaan Wanadesa dengan luas terkecil adalah Desa Tamanan yaitu 0,92 Ha, dengan luas efektif 0,74 Ha.

1. Desa Tamanan Kecamatan Banguntapan

Luas lahan Wanadesa di Desa Tamanan sebesar 0,92 Ha, dimana luas efektif $0,74 \mathrm{Ha}$ dan luas tidak efektif 0,18 Ha. Untuk lahan tidak efektif di Desa Tamanan, lokasi dekat dengan sungai Gajahwong dimana ditumbuhi dengan tanaman bambu dan tanaman buah yang sudah tumbuh menaungi lahan.

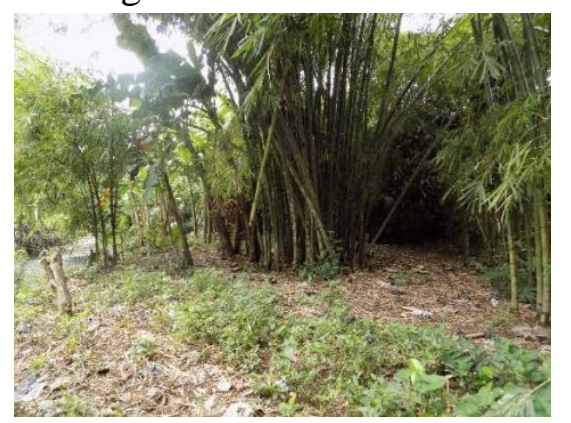

Gambar 1. Kondisi lahan

Wanadesa di Desa Tamanan,

Kecamatan Banguntapan

Tabel 2. Jumlah Vegetasi Eksisting di Lahan Wanadesa Desa Tamanan

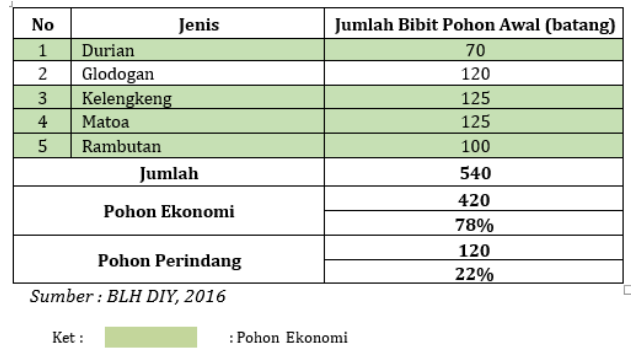


2. Desa Singosaren Kecamatan Banguntapan

Lokasi Wanadesa di Desa Singosaren seluas 1,64 Ha yang berada di lokasi dekat sungai Gajahwong. Kondisi lokasi sebagian besar tanah lapang yang memungkinkan penanaman lebih efektif yang luasnya mencapai 1,29 Ha, sedangkan untuk luasan 0,35 berada disekitar bantaran sungai Gajahwong. Untuk lahan tidak efektif di Desa Singosaren, lokasi berada di bantaran sungai Gajahwong dimana ditumbuhi dengan tanaman jati dan tanaman buah yang sudah tumbuh menaungi lahan. Kemudian untuk lahan yang efektif kondisi lahan hanya dimanfaatkan untuk menanam rumput kolonjono sebagai pakan ternak serta palawija

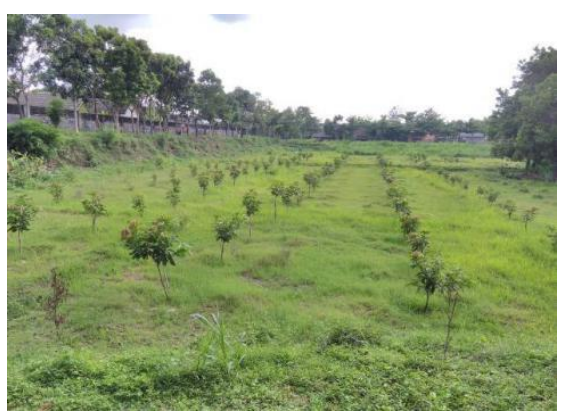

Gambar 2. Kondisi Lahan Wanadesa di Singosaren, Kecamatan Banguntapan
Tabel 3. Jumlah Vegetasi Eksisting di Lahan Wanadesa Desa Singosaren

\begin{tabular}{|c|c|c|}
\hline No & Jenis & Jumlah Bibit Pohon Awal (batang) \\
\hline 1 & \begin{tabular}{|l|} 
Alpukat \\
\end{tabular} & 100 \\
\hline 2 & Asam Jawa & 200 \\
\hline 3 & Buah Naga & 200 \\
\hline 4 & \begin{tabular}{|l|} 
Durian \\
\end{tabular} & 150 \\
\hline 5 & Glodogan & 150 \\
\hline 6 & Jambu Mete & 200 \\
\hline 7 & \begin{tabular}{|l|} 
Kelengkeng \\
\end{tabular} & 200 \\
\hline 8 & Mangga & 200 \\
\hline 9 & Matoa & 150 \\
\hline 10 & Merbau & 238 \\
\hline 11 & Palem & 30 \\
\hline 12 & Pucuk Merah & 200 \\
\hline 13 & Rambutan & 150 \\
\hline 14 & Sirsat & 160 \\
\hline \multirow[t]{2}{*}{15} & Keben & 150 \\
\hline & Jumlah & 2478 \\
\hline \multirow{2}{*}{\multicolumn{2}{|c|}{ Pohon Ekonomi }} & 1860 \\
\hline & & $75 \%$ \\
\hline \multirow{2}{*}{\multicolumn{2}{|c|}{ Pohon Perindang }} & 618 \\
\hline & & $25 \%$ \\
\hline
\end{tabular}

3. Desa Wirokerten Kecamatan Banguntapan

Lokasi Wanadesa di Desa Wirokerten seluas 3,09 Ha yang berada di lokasi dekat Sungai Gajah wong. Lokasi desa Wirokerten merupakan lokasi yang paling luas. Lokasi sebagian tertata (Lokasi 2 dan 3) dimana daerah tersebut dikelilingi akses jalan yang memungkinkan untuk kegiatan wisata. Sampai saat ini sudah digunakan untuk bumi perkemahan. Sebagian besar tanah lapang yang memungkinkan penanaman lebih efektif yang luasnya mencapai 2,22 Ha, sedangkan untuk luasan 1,73 dengan vegetasi jati, acasia serta sebagian sengon 


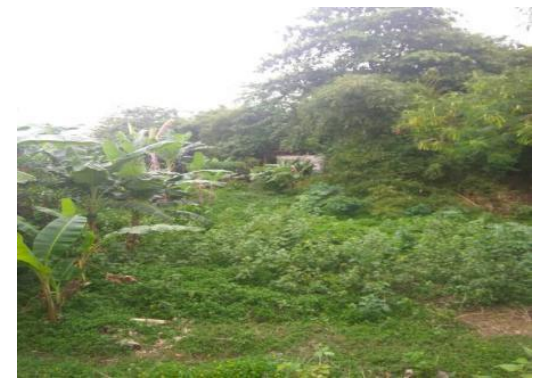

Gambar 3. Kondisi Lahan Wanadesa di desa Wirokerten, Kecamatan Banguntapan

Tabel 4. Jumlah Vegetasi Eksisting di Lahan Wanadesa Desa Wirokerten

\begin{tabular}{|c|c|c|}
\hline No & Jenis & Jumlah Bibit Pohon Awal (batang) \\
\hline 1 & Alpukat & 100 \\
\hline 2 & Asam Jawa & 200 \\
\hline 3 & Buah Naga & 200 \\
\hline 4 & Durian & 150 \\
\hline 5 & Glodogan & 150 \\
\hline 6 & Jambu Mete & 200 \\
\hline 7 & Kelengkeng & 200 \\
\hline 8 & Mangga & 200 \\
\hline 9 & Matoa & 150 \\
\hline 10 & Merbau & 238 \\
\hline 11 & Palem & 30 \\
\hline 12 & Pucuk Merah & 200 \\
\hline 13 & Rambutan & 150 \\
\hline 14 & Sirsat & 160 \\
\hline 15 & Keben & 150 \\
\hline & Jumlah & 2478 \\
\hline \multirow{2}{*}{\multicolumn{2}{|c|}{ Pohon Ekonomi }} & 1860 \\
\hline & & $75 \%$ \\
\hline \multirow{2}{*}{\multicolumn{2}{|c|}{ Pohon Perindang }} & 618 \\
\hline & & $25 \%$ \\
\hline
\end{tabular}

Tabel 5. Daftar tingkat hidup Tanaman Vegetasi

\begin{tabular}{|l|l|c|}
\hline \multicolumn{1}{|c|}{ Desa/Dusun } & \multicolumn{1}{|c|}{ Lokasi } & Tingkat Hidup \\
\hline Singosaren III & Selatan Ringroad & $90 \%$ \\
\hline Desa Tamanan & Selatan Ringroad & $15 \%$ \\
\hline Wirokerten ( Lokasi1) & Bantaran sungai & $15 \%$ \\
& berbatasan dengan Dusun & \\
& Nglebeng & \\
Wirokerten ( Lokasi 2) & Dusun Kepuh Wetan & $80 \%$ \\
Wirokerten ( Lokasi3 ) & Dusun Kepuh Wetan & $60 \%$ \\
\hline
\end{tabular}

Sumber : Data Survei, 2017

Pengembangan Pengelolaan Wanadesa Kabupaten Bantul meliputi;

1. Penyiapan Kelembagaan
Kelompok pengelola diarahkan untuk melaksanakan persiapan pembuatan Wanadesa antara lain :

a. Mengikuti sosialisasi penyuluhan dan pelatihan.

b. Menyusun rancangan kegiatan bersama-sama Pendamping.

c. Menyiapkan lahan miliknya untuk lokasi kegiatan pembuatan tanaman.

d. Menyelenggarakan pertemuanpertemuan kelompok pengelola Wanadesa.

e. Menyiapkan administrasi kelompok pengelola Wanadesa.

f. Menyusun perangkat aturan/kesepakatan internal kelompok pengelola Wanadesa.

2. Penataan Areal Tanaman Kegiatan penataan areal tanaman dilakukan dengan tahapan sebagai berikut:

a. Pemancangan tanda batas dan pengukuran lapangan, untuk menentukan luas serta letak yang pasti sehingga memudahkan perhitungan kebutuhan bibit.

b. Penentuan arah larikan.

c. Penentuan tempat penampungan sementara bibit yang akan ditanam.

3. Pembuatan Sarana dan Prasarana Pembuatan Gardu pandang/ Gazebo atau rumah peristirahatan serta embung bila dimungkinkan Pembuatan jalan inspeksi/setapak 
dan atau jembatan di dalam lokasi tanaman hutan rakyat, jika diperlukan.

4. Penanaman

Pola tanam dapat dikembangkan sesuai dengan kondisi lahan sebagai berikut :

a). Pola tanam di lahan terbuka (lahan efektif penanaman)

1) Baris dan larikan tanaman lurus

Pola tanam ini sesuai untuk lahan dengan tingkat kelerengan datar tetapi tanah peka terhadap erosi. Larikan tanaman dibuat lurus dengan jarak tanam teratur dan jumlah tanaman 400 Batang/Ha

2) Tanam jalur dengan pola tumpangsari.

Pola tanam ini sesuai untuk lahan dengan tingkat kelerengan datar s/d landai dan tanah tidak peka terhadap erosi. Larikan tanaman dibuat lurus dengan jarak tanam teratur. Karena menggunakan pola tanam tumpangsari, maka jarak tanaman antar jalur perlu lebih lebar dengan jumlah tanaman 400 batang/Ha. Diantara tanaman pokok dapat dimanfaatkan untuk tumpangsari tanaman semusim, dan atau tanaman sela

3) Penanaman searah garis kontur.

Pola tanam ini sesuai untuk lahan dengan kelerengan agak curam s/d curam. Penanaman dilakukan dengan sistim cemplongan dengan jumlah tanaman 400 Batang/Ha

b).Pola tanam di lahan terdapat vegetasi (Lahan kurang efektif penanaman)

Pada umumnya di lahan tegalan sudah terdapat tanaman kayu-kayuan maupun tanaman buah-buahan. Dalam rangka pengembangan Wanadesa, pada lahan tegalan yang jumlah pohon dan anakannya lebih dari 200 batang/Ha dapat dilakukan pengkayaan tanaman. Tanaman baru pengkayaan pada lahan tegakan maksimum 200 batang/Ha.

Pola penanaman di lahan tegalan meliputi :

1) Penanaman pengkayaan pada batas pemilikan lahan

2) Penanaman pengkayaan/ sisipan

5. Pemeliharaan Tanaman

Pemeliharaan tanaman dilakukan sampai tahun ketiga, yaitu pemeliharaan I pada tahun kedua dan pemeliharaan II pada tahun ketiga. Komponen pekerjaan pemeliharaan I meliputi :

1) Penyiangan

2) Pendangiran

3) Penyulaman

Jumlah bibit untuk penyulaman pada pemeliharaan I sebanyak $20 \%$ dari jumlah tanaman yang ditanam pada tahun pertama. 
4) Pemupukan : Dilakukan pemupukan dengan pupuk kandang/ buatan sesuai takaran.

5) Penyiraman : Dilakukan pada musim kemarau untuk menjaga tanaman dari kematian, hal ini terutama pada pembuatan tanaman sistem pot.

6) Perlindungan dan Pengamanan Tanaman Perlindungan tanaman meliputi kegiatan pemberantasan hama dan penyakit serta pencegahan dari bahaya kebakaran. Pengamanan dilakukan untuk mencegah kerusakan hutan dari berbagai macam gangguan.

Pemeliharaan tanaman dapat dilakukan dengan ketentuan sebagai berikut:

(1) Pemeliharaan I dilakukan jika keberhasilan persentase tumbuh tanaman setelah sulaman tahun berjalan $60 \%$, dan pemeliharaan tahun kedua bila persentase tumbuh tanaman pemeliharaan tahun pertama $80 \%$.

(2) Tanaman yang pada tahun pertama dan kedua persentasi tumbuhnya kurang dari yang ditentukan tersebut dipelihara secara swadaya masyarakat

Komponen pekerjaan pemeliharaan II meliputi :

1) Penyiangan

2) Pendangiran

3) Perlindungan dan pengamanan tanaman

Pengembangan Vegetasi
Pengembangan vegetasi adalah Jenis vegetasi yang akan dipakai untuk menggantikan vegetasi yang mati/ rusak. Jenis vegetasi yang diusulkan adalah sesuai dengan jenis vegetasi eksisting

Tabel 6. Jumlah dan Jenis Vegetasi Pengganti di Lahan Wanadesa Desa Tamanan

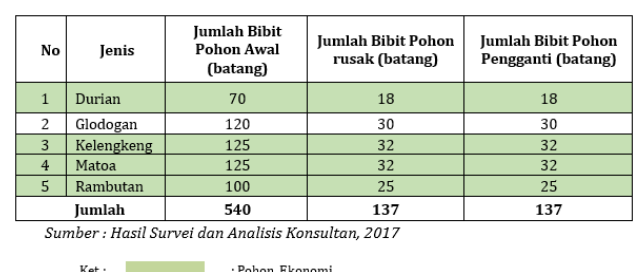

Tabel 7. Jumlah dan Jenis Vegetasi Pengganti di Lahan Wanadesa Desa Singosaren

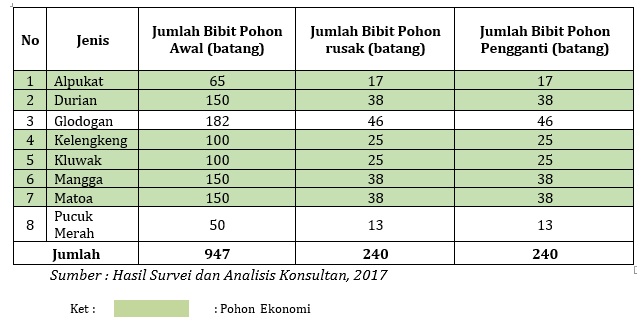

Tabel 8. Jumlah dan Jenis Vegetasi Pengganti di Lahan Wanadesa Desa Wirokerten

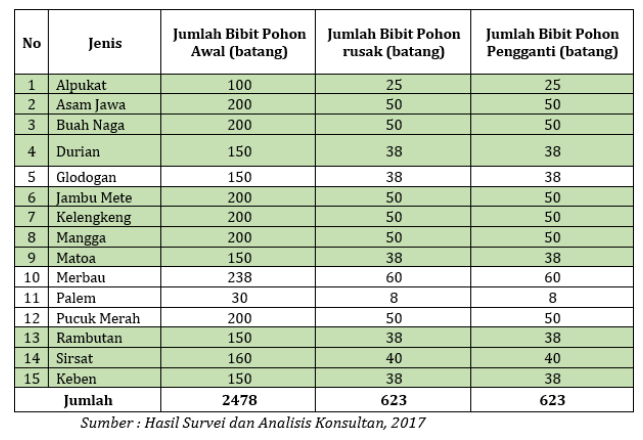

Ket: $\quad$ : Pohon Ekonomi 
Jumlah Vegetasi dan biaya

Jumlah pohon pengganti pohon yang rusak maka dihitung biaya penanaman yang meliputi bibit pohon dan biaya penanaman

Tabel 9. Jumlah dan Biaya Penanaman Pohon Pengganti di Lahan Wanadesa Desa Tamanan

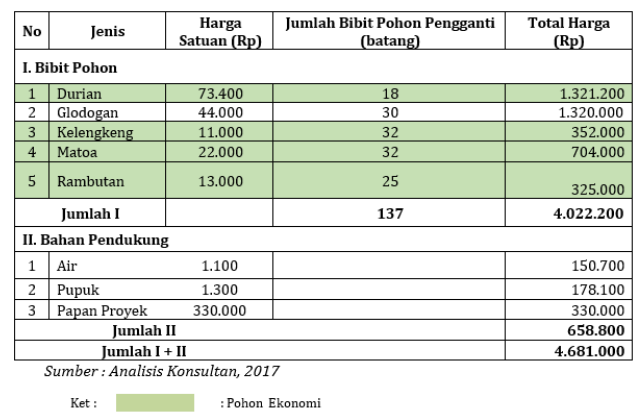

Tabel 10. Jumlah dan Biaya Penanaman Pohon Pengganti di Lahan Wanadesa Desa Singosaren

\begin{tabular}{|c|c|c|c|c|}
\hline No & Jenis & $\begin{array}{l}\text { Harga Satuan } \\
\quad \text { (Rp) }\end{array}$ & $\begin{array}{l}\text { Jumlah Bibit Pohon } \\
\text { Pengganti (batang) }\end{array}$ & Total Harga (Rp) \\
\hline \multicolumn{5}{|c|}{ I. Bibit Pohon } \\
\hline 1 & \begin{tabular}{|l|} 
Alpukat \\
\end{tabular} & 85.000 & 17 & 1.445 .000 \\
\hline 2 & Durian & 73.400 & 38 & 2.789 .200 \\
\hline 3 & Glodogan & 44.000 & 46 & 2.024 .000 \\
\hline 4 & \begin{tabular}{|l|} 
Kelengkeng \\
\end{tabular} & 11.000 & 25 & 275.000 \\
\hline 5 & \begin{tabular}{|l} 
Kluwak \\
\end{tabular} & 82.500 & 25 & 2.062 .500 \\
\hline 6 & Mangga & 92.000 & 38 & 3.496 .000 \\
\hline 7 & Matoa & 22.000 & 38 & 836.000 \\
\hline 8 & $\begin{array}{l}\text { Pucuk Merah } \\
\end{array}$ & 55.000 & 13 & 715.000 \\
\hline & Jumlah I & & 240 & 13.642 .700 \\
\hline \multicolumn{5}{|c|}{ II. Bahan Pendukung } \\
\hline 1 & Air & 1.100 & & 264.000 \\
\hline 2 & Pupuk & 1.300 & & 312.000 \\
\hline 3 & \begin{tabular}{|l|} 
Papan \\
Proyek
\end{tabular} & 330.000 & & 330.000 \\
\hline \multirow{2}{*}{\multicolumn{4}{|c|}{\begin{tabular}{|l} 
Jumlah II \\
Jumlah I + II
\end{tabular}}} & 906.000 \\
\hline & & & & 14.548 .700 \\
\hline
\end{tabular}

Tabel 11. Jumlah dan Biaya Penanaman Pohon Pengganti di Lahan Wanadesa Desa Wirokerten

\begin{tabular}{|c|c|c|c|}
\hline No & Jenis & Harga Satuan (Rp) & Total Harga (Rp) \\
\hline \multicolumn{4}{|c|}{ I. Bibit Pohon } \\
\hline 1 & Alpukat & 85.000 & 2.125 .000 \\
\hline 2 & Asam Jawa & 8.500 & 425.000 \\
\hline 3 & Buah Naga & 22.000 & 1.100 .000 \\
\hline 4 & Durian & 73.400 & 2.789 .200 \\
\hline 5 & Glodogan & 44.000 & 1.672 .000 \\
\hline 6 & Jambu Mete & 9.200 & 460.000 \\
\hline 7 & Kelengkeng & 11.000 & 550.000 \\
\hline 8 & Mangga & 92.000 & 4.600 .000 \\
\hline 9 & Matoa & 22.000 & 836.000 \\
\hline 10 & Merbau & 132.000 & 7.920 .000 \\
\hline 11 & Palem & 66.000 & 528.000 \\
\hline 12 & Pucuk Merah & 55.000 & 2.750 .000 \\
\hline 13 & Rambutan & 13.000 & 494.000 \\
\hline 14 & Sirsat & 40.300 & 1.612 .000 \\
\hline 15 & Keben & 27.500 & 1.045 .000 \\
\hline & Jumlah I & & 28.906 .200 \\
\hline \multicolumn{4}{|c|}{ II. Bahan Pendukung } \\
\hline 1 & Air & 1.100 & 685.300 \\
\hline 2 & Pupuk & 1.300 & 809.900 \\
\hline 3 & Papan Proyek & 330.000 & 330.000 \\
\hline \multicolumn{3}{|c|}{ Jumlah II } & 1.825 .200 \\
\hline \multicolumn{3}{|c|}{ Jumlah I + II } & 30.731 .400 \\
\hline
\end{tabular}

Sumber : Analisis Konsultan, 2017

Ket:

: Pohon Ekonomi

\section{KESIMPULAN}

1. Wanadesa adalah suatu kegiatan pendayagunan lahan desa dengan menambah atau meningkatkan jumlah tanaman (vegetasi) yang bertujuan meningkatkan ruang bebas guna mendukung upaya konservasi lingkungan.

2. Pengembangan pengelolaan Wanadesa di Kabupaten Bantul dilakukan dengan beberapa upaya meliputi penyiapan kelompok lembaga pengelola melalui penyuluhan dan penyusunan perangkat aturan/kesepakatan internal kelompok pengelola Wanadesa, penataan Areal tanaman di lahan Wanadesa, pembuatan sarana prasarana pendukung, penanaman serta pemeliharaan tanaman 
3. Luas lahan Wanadesa Desa Tamanan 0,92 Ha yang terbagi dalam luasan lahan efektif sebesar 0,74 Ha, sedangkan lahan kurang efektif seluas $0,18 \mathrm{Ha}$

4. Luas lahan Wanadesa Desa Singosaren 1,64 Ha yang terbagi dalam luasan lahan efektif sebesar 1,29 Ha, sedangkan lahan kurang efektif seluas $0,35 \mathrm{Ha}$

5. Luas lahan Wanadesa Desa Wirokerten 2,43 Ha yang terbagi dalam luasan lahan efektif sebesar 2,22 Ha, sedangkan lahan kurang efektif seluas 0,21 Ha,

6. Jumlah tanaman awal di lahan Wanadesa Desa Tamanan sebanyak 540 batang, jumlah tanaman yang rusak dan diganti sebanyak 137 batang dengan jumlah biaya penanaman sebesar Rp. 4.681 .000

7. Jumlah tanaman awal di lahan Wanadesa Desa Singosaren sebanyak 947 batang, jumlah tanaman yang rusak dan diganti sebanyak 240 batang dengan jumlah biaya penanaman sebesar Rp. 14.548.700

8. Jumlah tanaman awal di lahan Wanadesa Desa Wirokerten sebanyak 2478 batang, jumlah tanaman yang rusak dan diganti sebanyak 623 batang dengan jumlah biaya penanaman sebesar Rp. 70.731.400.

\section{SARAN}

Pengelolaan dan pengembangan lahan Wanadesa dapat ditingkatkan dengan kerjasama dengan pihak swasta maupun CSR dalam pembiayaan baik investasi maupun pemeliharaan.

\section{DAFTAR PUSTAKA}

1. Undang-undang RI Nomor: 41 Tahun 1999 tentang Kehutanan.

2. Peraturan Menteri Lingkungan Hidup No.1 Tahun 2012 tentang Menuju Indonesia Hijau.

3. Peraturan Gubernur (PERGUB) DIY No 91 Tahun 2016 tentang Wanadesa.

4. http://bungendrowaluyo.blogspot. com/2014/01/pengertianwanadesa.html

5. Sitorus, S.R.P., 2016. Perencanaan Penggunaan Lahan. Institut Pertanian Bogor.

6. Waluyo, E 2014 page 2 